\title{
Toward a Resilient Holistic Supply Chain Network System: Concept, Review and Future Direction
}

\author{
Junwei Wang, Raja R. Muddada, Hongfeng Wang, Jinliang Ding, Senior Member, IEEE, Yingzi Lin, \\ Changli Liu, and Wenjun Zhang, Senior Member, IEEE
}

\begin{abstract}
The recent financial crisis and other major crises have suggested that there are some strong interactions and interdependence between several supply chains and their external environments in various ways. A set of supply chains that are interdependent is called a holistic supply chain network (H-SCN) in this paper. There is a need to focus on building the resilience (in short, the ability of a system to recover from damage or disruption) of an entire $\mathrm{H}-\mathrm{SCN}$ as it is believed that such a network system is strongly relevant to the recent economic recession that is triggered by financial crises. The objectives of this paper are to provide a classification of different SCNs in literature, leading to the identification of a new type of SCN system, i.e., an H-SCN, and to discuss the state of knowledge on the resilience of SCNs, particularly of an H-SCN. A systematic review approach is applied in this paper. Another contribution of this paper is the provision of a more comprehensive definition and description of resilient systems, including SCN systems. A final contribution of this paper is the proposal of the future directions of research on resilient SCN systems, particularly resilient H-SCN systems.
\end{abstract}

Manuscript received December 28, 2013; revised April 30, 2014 and July 21, 2014; accepted July 24, 2014. The work of J. Wang was supported by the University of Hong Kong through the Seed Funding Programme for Basic Research under Grant 201409159015. The work of W. Zhang was supported by the Natural Sciences and Engineering Research Council of Canada through a Strategic Project Grant. The work of C. Liu was supported by the East China University of Science and Technology through a program of the Fundamental Research Funds for the Central Universities. The work of $\mathrm{H}$. Wang was supported by the National Natural Science Foundation of China (NSFC) under Grant 71001018. The work of J. Ding was supported in part by the NSFC Project under Grant 61273031, by the Program for New Century Excellent Talents in University under Grant NCET-12-0104, and by the Fundamental Research Funds for the Central Universities under Grants N120508001 and N130108001. (Corresponding author: Wenjun Zhang.)

J. Wang was with the Complex Systems Research Center, East China University of Science and Technology, Shanghai 200237, China. He is now with the Department of Industrial and Manufacturing Systems Engineering, Faculty of Engineering, The University of Hong Kong, Pokfulam, Hong Kong (e-mail: jwwang@hku.hk).

R. R. Muddada is with the Advanced Engineering Design Laboratory, Department of Mechanical Engineering, College of Engineering, University of Saskatchewan, Saskatoon, SK S7N 5A9, Canada (e-mail: rmm864@mail. usask.ca).

$\mathrm{H}$. Wang is with the Institute of Systems Engineering, Northeastern University, Shenyang 110819, China (e-mail: hfwang@ mail.neu.edu.cn).

J. Ding is with the State Key Laboratory of Synthetical Automation for Process Industry, Northeastern University, Shenyang 110819, China (e-mail: jinliang.ding@gmail.com).

Y. Lin is with the Department of Mechanical and Industrial Engineering, College of Engineering, Northeastern University, Boston, MA 02115 USA (e-mail: yilin@coe.neu.edu).

C. Liu and W. Zhang are with the Complex Systems Research Center, East China University of Science and Technology, Shanghai 200237, China, and also with the Advanced Engineering Design Laboratory, Department of Mechanical Engineering, College of Engineering, University of Saskatchewan, Saskatoon, SK S7N 5A9, Canada (e-mail: Chris.Zhang@usask.ca).

Color versions of one or more of the figures in this paper are available online at http://ieeexplore.ieee.org.

Digital Object Identifier 10.1109/JSYST.2014.2363161
Index Terms-Resilience, supply chain network (SCN), systematic review.

\section{INTRODUCTION}

$\mathbf{O}$ VER the past few decades, manufacturing strategies have continuously evolved to satisfy four major attributes of consumer products: 1) cost; 2) quality; 3) usability; and 4) availability (or delivery time). Supply chain management (SCM) has played a vital role in delivering support to achieve the aforementioned attributes (adapted from the work in [1]). During the 1980s and the 1990s, SCM was merely treated as a problem of intraorganizational logistical management. Most of the models are developed to solve for the optimal lot size [2]-[5], order quantity [6], and architectural decision to reduce the total cost of a product.

However, factors such as core competence, globalization, improved transportation structures and services, and ever-growing information and communication technologies have gradually evolved the supply chains to form interorganizational supply chain networks (SCNs) [7], [8]. For instance, the recent financial crisis of some big automotive companies and other major crises have all suggested that there are interactions and interdependence among several supply chains and that interactions and interdependence be addressed [9]. In this paper, a system that consists of several supply chains is called an interorganization or holistic SCN (H-SCN), the notion of which was first proposed in [10]. Clearly, there is a need to focus on building the resilience (in short, the ability of a system to recover from damage or disruption) of an $\mathrm{H}-\mathrm{SCN}$ in order to avoid global economic recession. In fact, there is a great deal of confusion in existing literature regarding the definition of an $\mathrm{SCN}$ and its resilience. This paper first provides a clarification of confusions regarding the terminology in SCM and proposes a classification of SCNs through a systematic literature review process, and then, it discusses the future directions of research on resilient SCN systems, particularly resilient $\mathrm{H}$-SCN systems.

A systematic review technique is employed for the comprehensive coverage and analysis of related literature. According to the work in [11], the term "systematic review" refers to a specific methodology of research, which was developed in order to gather and evaluate the available evidence pertaining to a focused topic. The primary question for this review is: what is our knowledge regarding a resilient SCN? Since it was felt at the point this review was conducted, there was some confusion existing in literature regarding the definition of an SCN. The secondary question is thus spilled out from the primary question, which is: what is an $S C N$ ? The review was conducted to answer the secondary question first and then to answer the primary question. This order was based on our preliminary observation that a large portion of literature used the term "SCN," but in fact, the system they were actually 
concerned takes a serial structure (i.e., strictly a chain) instead of a network. Therefore, the clarification of the concept of SCN systems seems to be necessary.

Another methodological consideration was regarding the criteria for what a resilient supply chain system is about. This is important as the answer to this question will serve as a basis for evaluating various research works claiming themselves as research on the resilient SCN. Therefore, prior to the intended systematic review, a more comprehensive definition of resilient systems, particularly in the context of supply systems, was developed. Finally, the systematic review methodologies described in [12]-[15] were followed. It is to be noted that a more rigorous methodology "metaanalysis" was not taken in this review. This is mainly because the object or product (i.e., literature) is more qualitative in nature and it is difficult to establish variables and moderators for a metaanalysis process [16].

This paper is organized as follows. In Section II, two backgrounds are discussed; the first is the definition of resilience, and the second is the definition of a supply chain and its related concepts. In Sections III and IV, this paper will provide a review of the concept of SCNs and the concept of resilient supply chain systems, respectively. In Section V, the future directions of research on resilient H-SCNs are described.

\section{General Understanding of Supply CHAIN AND ITS RESILIENCE}

\section{A. Supply Chain and SCM}

In general, a supply chain is a group of entities that are involved in a chain of processes concerning the procurement of raw materials or components, their conversion and/or assembly into a product, and the delivery of the final product to a customer [17]. Lamming et al. [18] referred the origin of "SCM" to the early 1980s when it only represented the management of materials across different functional boundaries within an organization [19], [20], but it was later extended to include "upstream" production chains and "downstream" distribution channels [21]-[24]. The typical definition of the term SCM in [25] is as follows: "The supply chain refers to all those activities associated with the transformation and flow of goods and services, including their attendant information flows, from the sources of materials to end users. Management refers to integration of all these activities, both internal and external."

Costs are a main concern for SCM. There are several costs in a supply chain, such as the ordering cost, the inventory holding cost, the transportation cost, and the production and/or assembly cost (including the operating cost). Traditionally, SCM aims to reduce the sum of these costs by coordinating various activities in a supply chain. At the same time, it also tries to achieve customer satisfaction by improving the delivery time, the product quality, and availability. Several strategies have evolved over the history to facilitate the achievement of these objectives as follows.

1) Mass customization: the capability of companies to offer individually tailored products or services on a large scale, i.e., combining customization with mass production [26].

2) Lean practice: the reduction of wastes that are anything without adding value to a supply chain. Several further notions are related to this lean philosophy, such as just in time (JIT), total quality management, total preventive maintenance, and human resource management [27]. For example, the inventory is considered one of the nonvalueadding entities, and the appropriate practice of JIT inventory management is adopted. It is noted that JIT aims to reduce the inventory or work in the process to zero.

3) E-commerce and virtual organization: some of the modern supply chains enhanced with the power of the Internet and other communication systems embark on these new strategies to satisfy the demand of their customers. For more details on E-commerce and virtual organizations, see [8], and [28]-[31], respectively.

4) Hybrid strategy: the whole supply chain is divided into two parts at a dividing point called the "decoupling point," i.e., upstream and downstream, according to the work in [17]. The management strategy at the upstream activities is based on the forecast that is further based on the past information, whereas the management strategy at the downstream activities is based on the real demand from the present customer [17]. Multiple decoupling points in a global supply chain system were also discussed in [32], in which three different types of decoupling points were discussed, i.e., the product structure decoupling point, the supply structure decoupling point, and the demand transfer decoupling point.

\section{B. Resilience}

In this section, definitions of resilience in various fields are presented. Thereafter, some key characteristics of resilience from these definitions are observed, which will be used later for the systematic review of resilience in supply chain literature in this paper.

1) Resilience in material science: Resilience in material science is usually referred to as the ability of a material to return to its original shape after temporary deflection. The degree of recovery is measured on the speed of recovery [33]. The degree of resilience is also measured on the ratio of the energy returned to the energy applied to produce the deformation. The higher the ratio, the higher the resilience of the material is [33]. This ratio can be viewed as proportional to the percentage of rebouncing.

2) Human resilience: A critical review by Luthar et al. [34] referred to resilience as a dynamic process encompassing positive adaptation within the context of significant adversity. They considered an individual's exposure to significant threats or adversities and positive adaptation despite disruption to the development process.

An interesting distinction between recovery and resilience patterns was made based on the impact of a traumatic event on the normal functioning of a human, as shown in Fig. 1. Fig. 1 shows that a resilient individual does have major disruptions in its normal function during a traumatic event, but the effect is mild. Medium-level disruptions absorbed for the recovery pattern tend to first increase and then reach normal levels ultimately. The other two plots, i.e., delayed and chronic, are considered the patterns of nonresilient individuals.

3) Ecological and engineering resilience: Holling defined and distinguished engineering resilience and ecosystem resilience as two different and alternating paradigms [36]. His ideas on these systems are shown in Table I.

4) Information and communication resilience: Laprie [37] identified resilience in complex information and computer systems to have a similar notion as ecological resilience 


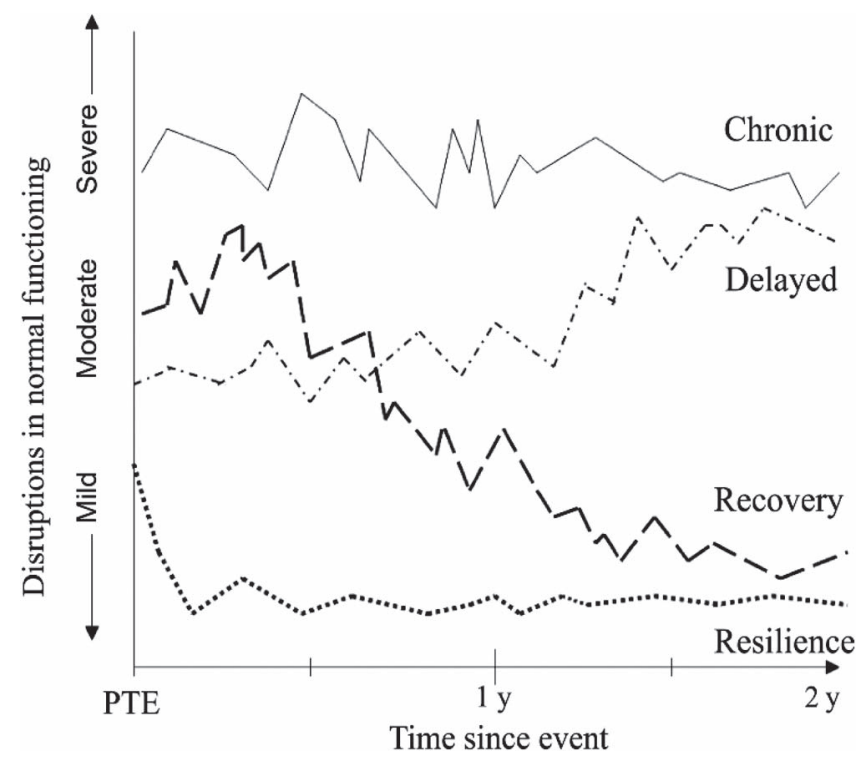

Fig. 1. Possible human responses after a traumatic event (adopted from the work in [35]).

TABLE I

Summary of ENGINEERING RESILIENCE VERSUS ECOLOGICAL RESILIENCE [36]

\begin{tabular}{|l|l|l|}
\hline & $\begin{array}{l}\text { Engineering } \\
\text { Resilience }\end{array}$ & Ecological Resilience \\
\hline $\begin{array}{l}\text { Definition } \\
\text { (focus on) }\end{array}$ & $\begin{array}{l}\text { Maintaining the } \\
\text { function. }\end{array}$ & Existence of the function \\
\hline $\begin{array}{l}\text { Attributes } \\
\text { (Desired for } \\
\text { fail-proof } \\
\text { design) }\end{array}$ & $\begin{array}{l}\text { Efficiency, } \\
\text { Constancy and } \\
\text { Predictability }\end{array}$ & $\begin{array}{l}\text { Persistence, Change, } \\
\text { and Unpredictability }\end{array}$ \\
\hline Stability & $\begin{array}{l}\text { Global } \\
\text { optimum or one } \\
\text { equilibrium } \\
\text { Steady State } \\
\text { exists }\end{array}$ & $\begin{array}{l}\text { More than one } \\
\text { equilibrium states and } \\
\text { systems flips states in } \\
\text { case of instabilities. }\end{array}$ \\
\hline $\begin{array}{l}\text { Measure of } \\
\text { Resilience }\end{array}$ & $\begin{array}{l}\text { Resistance to } \\
\text { Disturbance, } \\
\text { and Speed of } \\
\text { Return to } \\
\text { equilibrium }\end{array}$ & $\begin{array}{l}\text { Magnitude of } \\
\text { disturbance the system } \\
\text { can absorb before the } \\
\text { system changes its } \\
\text { structure and attain a } \\
\text { controlled behavior. }\end{array}$ \\
\hline
\end{tabular}

described by Holling [38]. For such a system, he provided the following definition of resilience: "The persistence of avoidance of failures that are unacceptably frequent or severe, when facing changes."

Sterbenz et al. [39] described the following two disciplines that serve as the basis of network resilience: 1) challenge tolerance disciplines that deal with the design and engineering of systems that continue to provide service in the face of challenges; and 2) trustworthiness disciplines that describe the measurable properties of resilient systems.

5) Business resilience: Hamel and Valikangas referred to business resilience as a superior capacity to reinvent a business model before circumstances force to change [40]. They further proposed the following strategies for business resilience:

a) anticipation of unexpected failures through close attention to the business environment;

b) investment in diversity (products or services);

c) constant exploration of new opportunities; d) maintaining the balance between optimization (a pursuit for efficiency) and the exploration of new opportunities.

6) General definition of a resilient system: The definitions of resilience gathered from various fields before are utilized to prescribe the characteristics of a resilient system and build a general definition for it. The general definition will be translated to a supply chain perspective in Section IV.

a) Objective: The objective of a resilient system is to survive and to maintain function (at least partially) in the course of disruption. For a supply chain, survival can be viewed as making profits, whereas the function of a supply chain can be viewed as meeting the demand with the supply. Here, the concepts of survival and functioning are separately made to capture a case where a supply chain meets the demand, but the demand is not enough to make profits for its survival.

b) Anticipation: A resilient system should have continuous anticipation for all kinds of disruptions by paying close attention to the constant changes in its environment and at the same time utilizing the knowledge learned from the past disruptive events.

c) Estimation: A resilient system should have a strong intent to estimate and prioritize damages that could occur from the anticipated disruptions.

d) Preparation: A resilient system should adopt a suitable resilient strategy or a combination of strategies as preparation for defending possible disruptions. Some of the resilient strategies as identified from the aforementioned are to build diversity, flexibility, redundancy, security and safety measures, collaboration, and sharing of resources. Which strategy is selected depends on the system, the context, and the situation. As an extension of the distinction made by Holling [36] between engineering resilience and ecological resilience, this paper believes that the supply chain system occupies the intersection of these two paradigms (see Table I) as it not only deals with the social component in the form of interactions with suppliers and customers but also concerns the engineering value during the production and manufacturing phase.

Combining the aforementioned characteristics, a general definition of a resilient system is suggested as follows: $A$ resilient system is a system with an objective to survive and maintain function even during the course of disruptions, provided with a capability to predict and assess the damage of possible disruptions, and enhanced by the strong awareness of its ever-changing environment and knowledge of the past events, thereby utilizing resilient strategies for defense against the disruptions. The proposed definition can be seen as a combination of the definitions of Zhang and Lin [41] and Hollnagel et al. [42]. Furthermore, the definition is applicable to SCN systems regardless of being a "linear chain" or a "network" system. The necessary attention to the general definition is paid to a particular system, e.g., information systems [41], [43], manufacturing systems [44], transportation systems [45], [46], SCN systems, etc., in the perspective of the structure of the particular system and the type of damages. For SCN systems, 


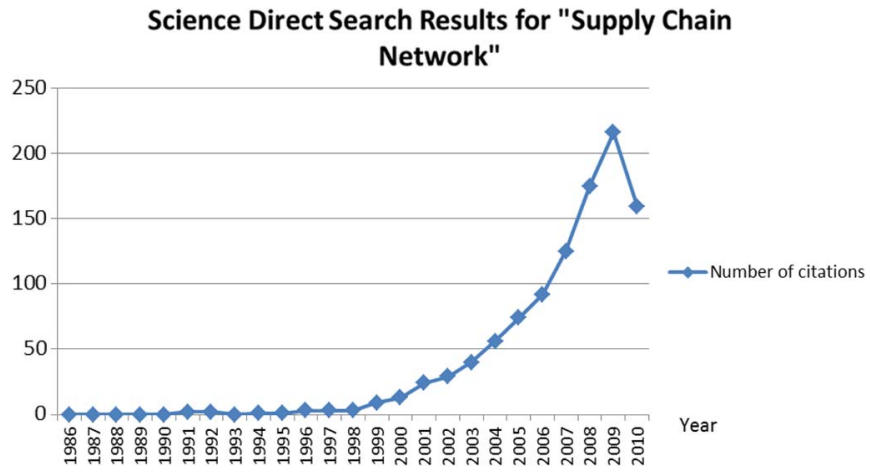

Fig. 2. Distribution of articles (in the ScienceDirect database) using the term SCN.

the damage at the system's behavior level is "supply fails to meet demand," which is a common notion in the community of the SCN system [47].

\section{SCNS: ORIGIN AND CLASSIFICATION}

In this section, the term "SCN" is clarified, and the classification of SCNs is thus studied. To achieve these objectives, we adopt a systematic review technique for examining literature. This includes two steps, i.e., data collection (i.e., searching relevant literature) and data analysis (i.e., examining the literature obtained).

\section{A. Literature Acquisition}

The following two online citation databases were selected for this paper:

1) ScienceDirect: www.sciencedirect.com;

2) Scopus: www.scopus.com.

These data sources comprehensively cover all major journals and magazines in the fields of supply chain, manufacturing, production, industrial engineering and operations research, including journals (e.g., European Engineering Management, the Journal of Operational Research, the International Journal of Production Research, Omega, IEEE Engineering Management, and Management Science). Three keywords (supply, chain, and network) were used with the following combinations: "supply network," "supply chain," and "network." The search was directed to all contents including the title of the article, the abstract, and the keywords in all the relevant journals and magazines. There was no restriction on the years of publication. This was done to find out the first use of the term SCN.

The search yielded a huge number of articles, and after applying filters in the respective websites, the ScienceDirect data source search yielded 1027 articles, and their distribution over the years is shown in Fig. 2. Fig. 2 shows the number of articles using the term SCN on the vertical axis and the corresponding years of publication on the horizontal axis.

A similar search on the database of Scopus has shown that 694 articles used the term SCN, and their distribution is shown in Fig. 3. Since the number of articles found is enormous, only 48 articles were chosen for the analysis based on their relevance to SCNs and popularity (the number of citations received). The article selection was also uniformly distributed over the years of publication proportional to the number of articles for the respective years.

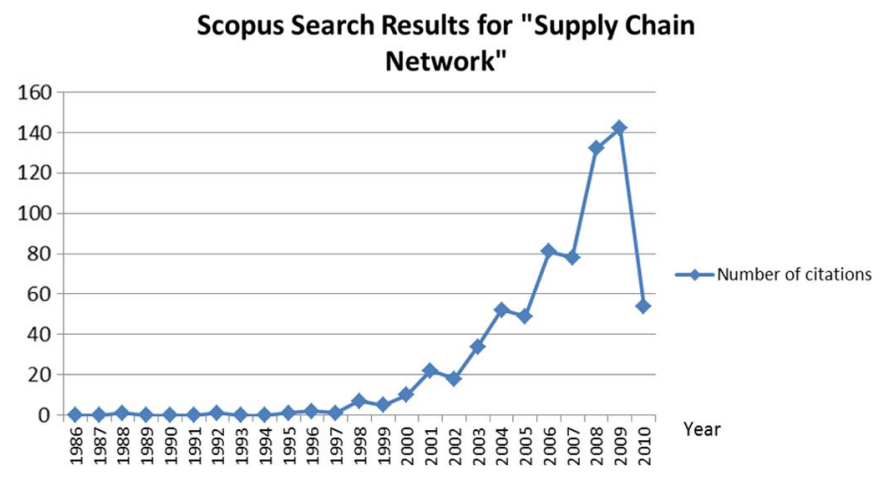

Fig. 3. Distribution of articles (in the Scopus database) using the term SCN.

TABLE II

Ambiguous UsAGE OF THE TERM SCN

\begin{tabular}{|l|}
\hline SCN-I \\
\hline Huchzermeier and Cohen (1996)[50], Zhou et al. \\
(1998)[64], Ross et al. (1998)[54], Dogan and \\
Goetschalckx (1999)[65], Min and Melachrinoudis \\
(1999)[66], Mirhassani et al. (2000)[67], Gjerdrum \\
et.al (2001)[57], Dong and Chen (2001)[68], \\
Raghavan and Viswanadham (2001)[69], Zhou et al. \\
(2002)[70], Dong et al.(2004)[71], Eskigun et al. \\
(2005)[72], Melo et al. (2006) [73], Choi et al. (2006) \\
[74], Liu and Zhou (2007)[75], Dong and Peng \\
(2007)[76], Chiou (2007)[77], Romeijn et al. \\
(2007)[78], Melo et al. (2009)[79], Che et al. \\
(2009)[80]. \\
\hline SCN-II \\
\hline Min and Melachrinoudis (1999)[66], Rupp and Ristic \\
(2000)[81], Tsiakis et al. (2001)[59], Nagurney et al. \\
(2002)[82], Cakravastia et al. (2002)[83], Lancioni et \\
al. (2003)[84], Chen et al. (2003)[85], Wathne and \\
Heide (2004)[86], Chen et al.(2004)[87], Dong et al. \\
(2004)[71], Chan and Chan (2004)[88], Jain et.al \\
(2004)[89], Santoso et al. (2005)[90], Altiparmak et \\
al. (2006)[91], Jiao et al. (2006)[92], Patnayakuni et \\
al. (2006)[93], Sha and Che (2006)[94], Ding et al. \\
(2006)[95]. \\
\hline H-SCN \\
\hline Lin and Shaw (1998)[55], Lin et al. (1999)[96], \\
Mirhassani et al. (2000)[67], Cox (2004)[97], Fandel \\
and Stammen (2004)[98], Ranganathan et al. \\
(2004)[99], Beamon and Fernandes (2004)[100], \\
Surana et al. (2005)[101], Sanders (2005)[102], \\
Wuming et al. (2009)[61]. \\
\hline
\end{tabular}

\section{B. Literature Analysis}

A preliminary analysis was performed on the search results with the help of the plots shown in Figs. 2 and 3, respectively. These plots indicate that the use of the term SCN became widely popular in supply chain literature at the beginning of years 1998 and 1999. Moreover, its usage kept increasing over the years, as shown in Figs. 2 and 3, respectively. It is to be noted that the drop in the curves in the last section of the plots is because only articles published until the middle of the year 2010 were collected. A further analysis was performed through the careful study of the selected 48 articles (as listed in Table II). As for the origin of the term SCN, the first among the authors to use this term based on the aforementioned search were Billington and Davis [48], Padillo et al. [49], Huchzermeier and Cohen [50], Correa and Miranda [51], Chandra [52], Lin et al. [53], Ross et al. [54], Lin and Shaw [55], and Srinvasan and Moon [56]. However, the first comprehensive definition and analysis of an SCN was not recorded 


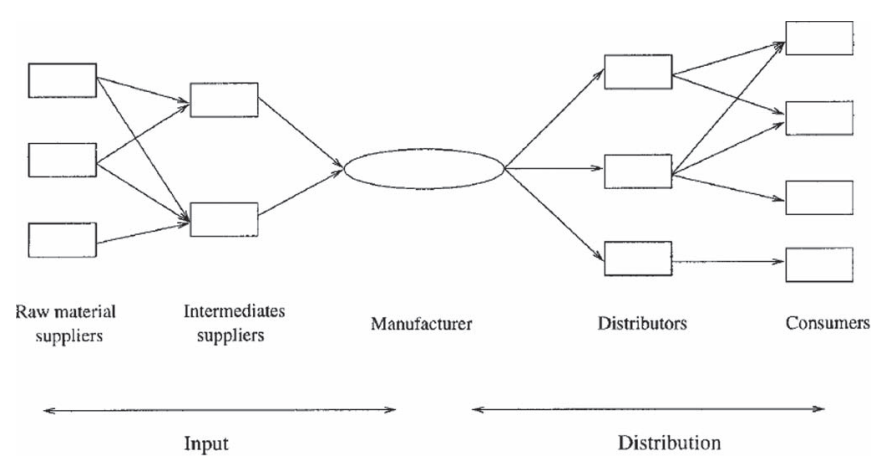

Fig. 4. Firm-centered SCNs (adapted from the work in [57]).

until Lin and Shaw [55]. According to them, "A supply chain network is a network of autonomous or semi-autonomous business entities involved, through upstream and downstream links, in the different processes and activities that produce goods or services to customers." Furthermore, they classified SCNs into three types based on seven attributes. However, the classification has not included the structural information of the network that distinguishes different supply chain systems.

The classification of SCNs is important because the increasing usage of the term SCN combined with no clear classification on its structure might cause some trouble for future researchers to identify and evaluate relevant literature. To address this concern, this paper identifies three network structures that might have been referred to as SCNs by earlier researchers in this field. They are illustrated in the following. The first type of SCNs contains a starlike structure. In this structure, various branches evolve from a single node to various parts of the network. Such a structure of an SCN is usually seen when the distribution of products is from a single manufacturing unit to various distribution units. All nodes in the network are under the control of a single management. The main management activity of this type of SCNs is the planning of the distribution activities of the products of a single firm at various geographical locations. Hereafter, this type of SCN is named as SCN-I. Fig. 4 illustrates SCN-I, which is adopted from the work in [57].

The second type of SCNs is a tier-based network system. In this structure, there are multiple instances of different firms at each stage in a supply chain. Such a structure is commonly seen when several supply chains exist to have common source nodes (suppliers) and destination nodes (customers). The nodes in this kind of networks are independent and not all under the control of a single management. The main management activities of this type of SCNs are planning and partner selection at the same tier level [28], [58]. Hereafter, this type of SCNs is named as SCN-II. Fig. 5 illustrates SCN-II. On a further note, this type of SCNs is centered on a particular industrial sector of products (e.g., the automotive sector), and the networks of SCN-II do not extend their reach beyond the industrial sector they belong to.

The third type of SCNs is defined as a set of supply chains that have interdependent relations. These supply chains are different in their nature; for example, one supply chain may be on a business to supply housing property, whereas another supply chain may be on a business to supply cars. For the convenience of subsequent discussions, let us call this type of SCNs SCN-III or H-SCN (see Fig. 6). A couple of remarks are made on the definition of an H-SCN.

Remark 1: Goods "traveling" over SCNs can be of three types, i.e., energy, material, and information or signal [9], [60].

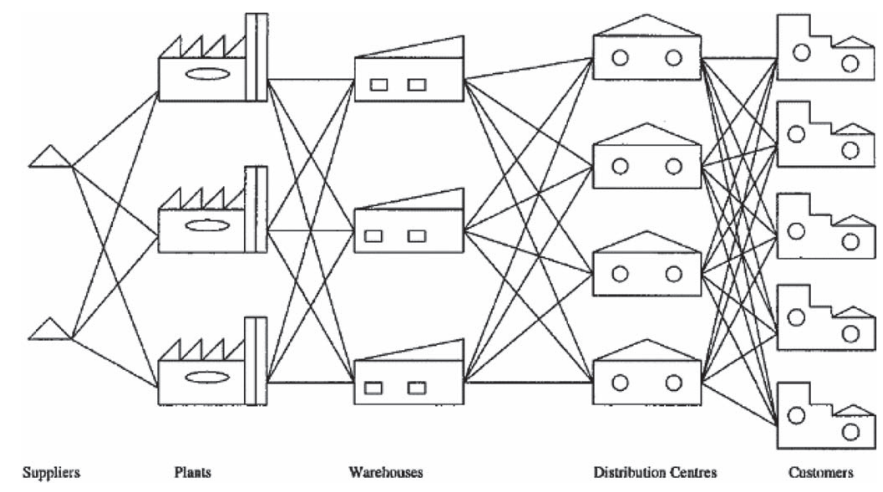

Fig. 5. Industry-centered SCNs (adapted from the work in [59]).
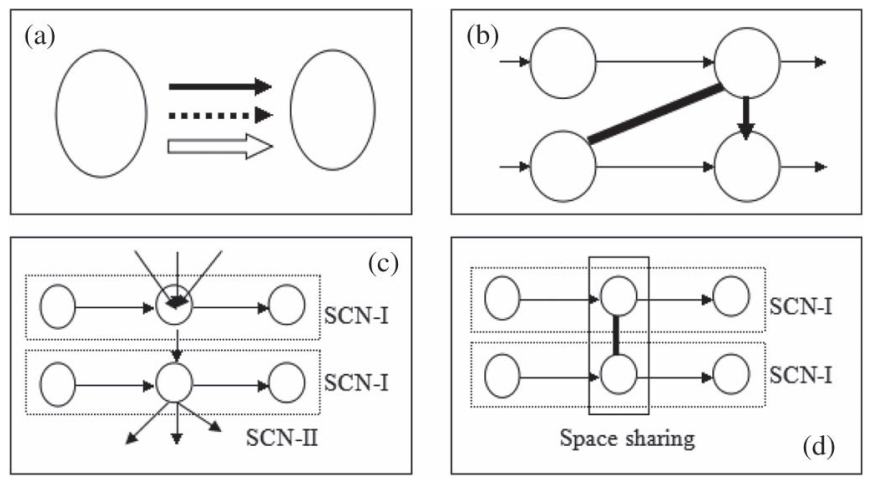

$\longrightarrow$ Energy $\longrightarrow$ Material $\ldots$ Signal

Non-directional constraint

Fig. 6. (a)-(d) H-SCN

Multiple flows of goods between any two entities of an SCN are allowed [see Fig. 6(a)].

Remark 2: Interdependence only happens between two entities of SCNs [see Fig. 6(b)]. Interdependence has two types, i.e., logical and physical. Logical interdependence involves the flows of goods, and it is directional [see Fig. 6(b)], whereas physical interdependence is about spatial and temporal constraints imposed on the multiple flows or entities of SCNs [see Fig. 6(b)]. Fig. 6(c) shows three supply chains (two with SCN-I and one with SCN-II) and their interaction. In particular, the supply chain of SCN-II crosses over two supply chains of SCN-I. Fig. 6(d) illustrates that two firms that belong to two different SCN-I systems share the same work space (e.g., building). An example of a temporal constraint over two flows of goods may be such that the two flows must start from their sources and arrive at their destinations at the same time, respectively.

Remark 3: The member (i.e., SCNs) in an $\mathrm{H}-\mathrm{SCN}$ can be of SCN-I and/or SCN-II or other H-SCNs. SCNs of this type are revisited in the last section of this paper, where the future directions of research are discussed.

\section{Discussion}

The term SCN has been widely used in contemporary literature. Its usage is ever growing and so is its ambiguity. According to the work in [1], "the origins of the notion of supply chain management (SCM) are unclear." Their view is in support to our observation. Although some classifications of SCNs are available in literature [55], [61], no clear terminology is available to distinguish the $\mathrm{SCN}$ structures and their respective 
scope of the purpose. This paper defined three types of SCNs based on their structure and scope of purposes (see the previous section)

The three types of SCNs previously discussed are used to classify the 47 selected works, and they are listed in Table II. Table II includes those that use the term SCN in literature but in an ambiguous manner. It is noted that Dubois et al. [62] did not use the term SCN, but they actually discussed the structural issue of an $\mathrm{H}-\mathrm{SCN}$, which is an example of confusion in literature regarding the term supply chain or SCN. The papers listed under $\mathrm{H}-\mathrm{SCN}$ in Table II have not discussed the particular management issue related to the $\mathrm{H}-\mathrm{SCN}$, which will be discussed in the last section of this paper. In fact, they were still on the SCNs of SCN-I or SCN-II as far as the management of the SCN is concerned. In these studies, the fact that a particular SCN of type I or type II may interact with other SCNs was at most viewed or modeled as somewhat "disturbances" or "boundary conditions" to that particular SCN of type I or type II. Such an idea can be seen in the study of Chan et al. [63], where they studied the supplier's flexibility to the manufacturer, particularly the following question: is a real-time control for the supplier's flexibility necessary? It is noted that, in [1], the term "networked supply chain" was used, which does not imply the recognition of an H-SCN. In fact, the system they termed is of SCN-II, which has some sense of network (see Fig. 5).

One of the most important needs to make the classification of SCNs is that different types of SCNs may call for different design and operation management approaches or techniques. For instance, upon the standing out of an $\mathrm{H}-\mathrm{SCN}$, how to manage it calls for further research. In the current literature, the studies of SCN-I and SCN-II mainly considered a serial structure, including four independent processes, i.e., material supply, manufacturing, logistics, and customers. The design of SCN-I and SCN-II is to determine the parameters of a starlike structure and a tier-based structure, respectively; the design of an $\mathrm{H}-\mathrm{SCN}$ is, however, to determine the parameters of the network structure. The management activities of SCN-I and SCN-II in the current literature have been summarized in Section III-A; however, the management of H-SCNs has not been studied in literature, except in our own preliminary work [10], [103]. Our previous work has shown that the design and management of H-SCNs will face the challenge of scalability issues [10], [103]. Furthermore, in the design and management of supply chain systems, modeling tools are necessary; in particular, there are mainly four types, i.e., spreadsheet, system dynamics, discrete-event dynamic system techniques, and business games [104]. All these tools can be employed for SCN-I and SCN-II; however, only discrete-event tools are appropriate for the $\mathrm{H}-\mathrm{SCN}$ systems due to the different structures and the related scalability issue, which was recently discussed in [103].

The classification of SCNs also provides a framework for future researchers to identify and present their works in the most relevant sections of SCM literature. It is also noted that, hereafter, the terms (supply chain and SCN) are used interchangeably; a chain is a special kind of network. In literature, there have been proposals that view a supply chain as a network [105], [106], but they did not have the clear notion of an $\mathrm{H}-\mathrm{SCN}$.

\section{RESILIENT SCN}

In this section, a review of the works related to the application of resilience in the field of SCM is presented. Note that the general definition of a resilient system is applicable to a resilient SCN system. A similar systematic review technique used in Section III was adopted for this review. The databases and the search methodology remained the same. The keywords used were shifted to various combinations of the words "supply chain," "SCN," "resilience," "resilient," and "resiliency." For the selection criteria, only the works that address resilience and its related issues in supply chains are selected. In addition to relevance, the number of citations was also taken into account. As a result, 43 articles were selected for the analysis, and the classification was made into four categories of resilient SCNs. These categories were developed based on the characteristics proposed in the definition of a resilient system in Section II-B. The categories are as follows.

1) Awareness and anticipation: The articles that stress on the identification and awareness of existing vulnerabilities and upcoming disasters in a supply chain.

2) Estimation and measurement: The articles that are focused on computation regarding the effect of a disruption or the effect of adopting alternative mitigation strategies.

3) Proactive defense: Proactive strategies are those that are in action even before a disruption takes place.

4) Reactive defense: Reactive strategies are those that are designed to perform a defensive action after damage or a disruption happens to the system.

Using the aforementioned four categories, 43 articles relevant to resilient SCNs were selected and grouped, as shown in Table III. Some of the key papers are commented in the following.

Christopher and Peck [107] provided an empirical study from several industrial supply chains. They discussed the concept of the interdependence of SCNs, but the network in their description seems to be SCN-II (see Fig. 5) with some relationships existing between two nonneighboring organizations, and these relationships seem to make sense for them to define and use the term "network." They elaborated on the nature of resilience, including internal vulnerability and external risks. They also proposed the design of systems into resilience with flexibility and redundancy. It is also very interesting to note that they recognized the difference between robustness and resilience, with the latter focusing on the shift of the stable or equilibrium state. They also elaborated the importance of information sharing and visibility, as well as planning. Their work has touched all the four characteristics of a resilient SCN. Their work is, however, qualitative in nature.

Sheffi [108] presented a similar discussion with Christopher and Peck [107] but with an interesting point that resilience can make a company to predict ahead. Another point that was added by Sheffi [108] is the cultural effect. He implied that different cultures of an organization can considerably change the resilience property or behavior of the company. However, his work landed on the SCN of type I and type II only.

A comprehensive discussion of the concepts of risk in supply chains of type I and type II was made in Deloitte's white paper [109]. This white paper also proposed the means to achieve resilience in an SCN system, i.e., visibility, flexibility, collaboration, and control. Carvalho and Machado [110] presented a very interesting work on the integration of lean, agile, resilience, and green paradigm for SCM. They used the cost as a common denomination for all the four means, and they discussed some conflicts among the four means. Their SCN is a serial structure (i.e., SCN-I). There may be some controversy with their proposition that all the four means are 
TABLE III

CLASSIFICATION OF RESILIENT SCNS

\begin{tabular}{|l|}
\hline Awareness and Anticipation \\
\hline Kong and Li (2008)[113], Xu 2008[114], Ji and Zhu \\
(2008)[115], Hammant and Braithwaite \\
(2007)[116], Carvalho and Machado (2007)[110], \\
Sheffi (2005)[108], Sheffi and Rice (2005)[117], \\
Klibi (2010)[118], Rice and Caniato (2003)[119], \\
Barnes and Oloruntoba (2005)[120], Craighead et al. \\
(2007)[121], Blackhurst et al. (2005)[111], \\
Christopher and Peck (2004)[107]. \\
\hline Estimation \\
\hline Deleris et al. (2004)[122], Glickman and White \\
(2006)[123], Babich (2006)[124]. Babich et al. \\
(2007)[125], Tang and Tomlin (2008)[126], Mitra et \\
al. (2009)[127], Jiang (2009)[128], Yu and Zhao \\
(2008)[129], Bakshi and Kleindorfer (2009)[130], \\
Rice and Caniato (2003)[119], Diabat et al. \\
(2012)[131], Wagner and Neshat (2009)[112], \\
Sheffi (2005)[108], Sheffi and Rice (2005)[117], \\
Wang et al. (2010)[43], Iakovou et al. (2010)[132], \\
Craighead et al.(2007)[121]. Christopher and Peck \\
(2004)[107]. \\
\hline Proactive Defense \\
\hline Slingo et al. (2005)[133], Glickman and White \\
(2006)[123], Sheffi (2005)[108], Sheffi and Rice \\
(2005)[117], Lodree and Taskin (2009)[134], \\
Sarathy (2006)[135], Carvalho and Machado \\
(2007)[110], Dynes (2008)[136], Mohan \\
(2009)[137], Rice and Caniato (2003)[119], More \\
and Babu (2009)[138], Enyinda and Tolliver \\
(2009)[139], Thun and Hoenig (2009)[140], Alonso \\
et al. (2009)[141], Lara and Shimon (2008)[142], \\
Thamilarasu, and Sridhar (2008)[143], Roussinov \\
and Chau (2008)[144], Weber (2010)[145], Barnes \\
and Oloruntoba (2005)[120], Knemeyer et al. \\
(2009)[146], Ratick et al. (2008)[147]. Christopher \\
and Peck (2004)[107]. \\
\hline Reactive Defense \\
\hline Yan et al. (2010)[148], Liu and Ji (2007)[149], \\
Vellema et al. (2006)[150], Boin et al. (2010)[151], \\
Stewart (2009)[152], Roh et al. (2011)[153], Thun \\
and Hoenig (2009)[140], Piplani and Sarawat \\
(2012)[154], Ivanov (2010)[155], Christopher and \\
Peck (2004)[107]. \\
\hline
\end{tabular}

aimed at reducing the cost. In fact, a lean SCN can certainly reduce the cost, but a resilient $\mathrm{SCN}$ may increase the cost if the redundancy design approach is taken. Blackhurst et al. [111] presented an empirical study on the management of disruptions in an SCN. First, their application model is of SCN-I or SCN-II. Second, they only gave the awareness of disruption, the likelihood of disruption, and its management. Another empirical study on disruption management was conducted by Wanger and Neshat [112]. Again, their study was for SCN-I or SCN-II systems.

The classification presented in Table III reveals that the exclusive use of the term resilience in the context of a supply chain is quite recent (2003-2004). It has been observed that supply chain literature suggests more of proactive defense approaches than of the reactive approach to achieve resilience in a supply chain. However, there is a great overlapping of the strategies for the management of resilient SCNs among various works in literature. Some of the most prominent strategies were found to be:

1) the identification of vulnerabilities (e.g., the "bullwhip" effect, etc.);

2) building redundancy (easy but costly);
3) building flexibility (cost effective but hard to build);

4) reconfigurations planning;

5) taking high security measure (costs can be reduced through collaboration).

The survey revealed that most of the works in resilient supply chains are qualitative in their nature. In addition, the main drawback of the aforementioned works is that the management strategies proposed are suitable to the SCNs of SCN-I or SCN-II but not suitable to an $\mathrm{H}-\mathrm{SCN}$.

\section{COnClusions And Future Directions of Work}

\section{A. Conclusions}

The concept of supply chains, i.e., SCNs, is not clear in the current literature. There are many uses of the term SCN, but essentially, they are chains in a serial structure only. This paper has proposed to classify SCNs (chains are considered the simplest network) into three types, i.e., SCN-I, SCN-II, and $\mathrm{H}-\mathrm{SCN}$, after generalizing the existing literature.

There have been many studies on the management of the first two types of SCNs but less work on the third type of SCNs (if none). There have been many studies on the management of the resilience of the first two types of SCNs but not that of H-SCNs. A fruitful result is available on the detection of vulnerable areas, the plan for emergency, and information sharing for achieving resilience with an SCN. However, these studies are not upon a clear definition of resilience.

As opposed to the complete definition of resilient systems given in Section II-B, the existing literature only provided partial knowledge on one or two aspects of resilience, e.g., vulnerability. In fact, the resilience of a system makes more sense on a highly networked system [41], [60]; in other words, the resilience of $\mathrm{H}$-SCNs being higher than that of the first two types of SCNs makes more sense. There are two reasons for this assertion. First, the resilience of an H-SCN has more impact to the economy of a societal system as the structure of an $\mathrm{H}-\mathrm{SCN}$ takes across different areas of economic and social units, e.g., financial institutions, manufacturing industries, healthcare systems, etc. Propagations of any bad effect in the operation of an H-SCN (e.g., the bullwhip effect, etc.) can be more uncertain (thus more vulnerable areas internally and more unanticipated events externally). Second, the higher the degree of "hybridization" and "diversity" in a system, the higher the resilience or chance to recovery after a system's mishap through the reconfiguration of the system in particular (see the ecological resilience of Holling [36]).

It is further noted that resilience, reliability, and robustness are distinct concepts [41], [156]; detailed discussion can be found in [156]. The current research on resilient SCNs is not built on the distinction of these concepts, except for the work of Christopher and Peck [107]. This situation can thus hinder further developments of theory for resilient SCNs.

\section{B. Future Directions of Research on H-SCN Systems}

The authors of this paper have further asserted that the lack of knowledge and awareness of H-SCNs and their resilience in our society is responsible for the financial crisis and the global economy recession. The fact that Japanese automobile parts supplies also suffer from the fall of American automobile industries has given evidence to our assertion. The resilience of individual firms (Japanese automobile manufacturers) does not 
ensure the resilience of the entire network (global automobile manufacturers). However, the falls of firms have time stamps, e.g., the fall of the American automobile industries first and then the fall of the Japanese automobile industries. The dynamics of the falls suggests a need to study the dynamic propagation of disruptions over an entire H-SCN in the future, i.e., Research Thrust I. There are a couple of issues in order to develop a tool to predict the propagation of disruptions over an entire $\mathrm{H}-\mathrm{SCN}$ system.

Issue 1: Measure of disruption. In literature [111], [157], [158], several reviews relevant to this issue are useful to addressing this issue. However, this paper has not been built on the classification of SCNs (i.e., three types, as concluded in this paper). Therefore, more clarification and classification of these measures proposed in literature is needed with a goal to adapt them to the H-SCN system. Furthermore, the current literature seems to be more on the SCNs of SCN-I or SCN-II. Therefore, a disruption makes more sense on a single firm but not on an entire network. Further research toward measures for an entire SCN system is warranted.

Issue 2: Dynamic propagation. The existing approach to propagation lands on SCNs of SCN-I and SCN-II. There is awareness of the need for employing some more sophisticated tool such as Petri nets to the dynamic propagation of disruptions [111], [172]. In our opinion, more specifically, there is a need to study the information acquisition and prediction accuracy as the accuracy of prediction relies on the information available and its quality. The information acquisition will become a basis for a regulatory body to develop policies and rules for an $\mathrm{H}-\mathrm{SCN}$ system, which is another future research problem (see later discussions in this paper).

Future research on the modeling and simulation of resilient $\mathrm{H}-\mathrm{SCN}$ systems for the effective design and management of H-SCN systems is urgently needed, i.e., Research Thrust II. The existing knowledge is not sufficient for the management of resilient H-SCNs; in fact, only a few studies were upon a holistic SCN, and they were more qualitative than quantitative (see discussions in Section IV). The modeling of an H-SCN system will be a useful step toward a systematic development of the knowledge of resilient H-SCN systems in all the four aspects (see both discussions in Sections II-B and IV), i.e., anticipation, estimation, proactive defense, and reactive defense. The modeling should take into consideration those well-known effects, such as the bullwhip effect [159], [160] or the Forrester effect [161], as those effects actually are the causes of the vulnerability of a whole network. Furthermore, the modeling should also take into account the different management strategies such as the hybrid strategy of Christopher [17], and so on, as they affect the performance of a whole network. Network theories need to be studied for their suitability for modeling an H-SCN system, including social networks [162], scale-free networks [163], and Petri nets [164]-[167].

Another future research is the regulation/coordination in an H-SCN system, i.e., Research Thrust III. It is clear that a complete "self-evolution" business approach in the business world is prone to failures, e.g., the financial crisis. This is perhaps due to the very nature of humans, i.e., competitiveness. Competitiveness can lead to "local minima," which has been shown to be true in evolutionary optimization techniques. Therefore, there is a need for research on a balanced regulation and "self-evolution" strategy for operation management. Such a tradeoff is believed to be dependent on a particular culture of a community where several supply chains cooperate, e.g., the spending culture, trustiness among business entities, etc. Finally, regulation/coordination should be studied for both the operation and recovery of an H-SCN system.

Finally, research should be directed toward the understanding of information sharing in an H-SCN system, i.e., Research Thrust IV. Information sharing should be a general principle in the management of an H-SCN. It is noted that information sharing has been widely studied in the area of SCM for SCN-I and SCN-II [17], [168], [169], [171] but not for H-SCN systems. Research particularly should be on the understanding of what type of information should be shared and how the sharing can be realized. Furthermore, studies of information sharing and regulation/coordination must be integrated simply because any information identified to be useful to the business continuity of an H-SCN system must be approved by regulation, whereas the nature of regulation/coordination in a market economic society is about information and its sharing of the business and the society but not about instructing how businesses should do their operations.

All the proposed studies, however, need to include human factors in the loop. The emphasis on the human factors has been implied by the awareness of the cultural effect on an organization in terms of resilience. The recent move on the International Organization for Standardization (ISO) 22301 that emphasizes the resilience of a whole society is hand-in-hand with the emphasis on the management of an $\mathrm{H}-\mathrm{SCN}$ advocated in our paper. Furthermore, methodologically, an H-SCN system should be considered a complex adaptive system by following the proposition of Surana et al. [101], although they did not have the notion of an H-SCN. Another methodological notion is that an $\mathrm{H}-\mathrm{SCN}$ system should be viewed as a highly uncertain and dynamic system (see the view of Simangunsong et al. [170] when they deal with SCN-I or SCN-II systems).

\section{REFERENCES}

[1] I. J. Chen and A. Paulraj, "Understanding supply chain management: Critical research and a theoretical framework," Int. J. Prod. Res., vol. 42, no. 1, pp. 131-163, 2004.

[2] G. Adler and R. Nanda, "The effects of learning on optimal lot size determination-Multiple product case," AIIE Trans., vol. 6, no. 1, pp. 21-27, 1974.

[3] P. Afentakis and B. Gavish, "Optimal lot sizing algorithms for complex product structures," Oper. Res., vol. 34, no. 2, pp. 237-244, Mar./Apr. 1986.

[4] P. H. Zipkin, "Computing optimal lot sizes in the economic lot scheduling problem," Oper. Res., vol. 39, no. 1, pp. 56-63, Jan./Feb. 1991.

[5] S. W. Shinn, "Determining optimal retail price and lot size under dayterms supplier credit," Comput. Ind. Eng., vol. 33, no. 3/4, pp. 717-720, Dec. 1997.

[6] E. J. Lodree, "EOQ revisited: The case of unequal and integral order quantities," Int. J. Prod. Econ., vol. 105, no. 2, pp. 580-590, Feb. 2007.

[7] L. Lu and G. Wang, "A study on multi-agent supply chain framework based on network economy," Comput. Ind. Eng., vol. 54, no. 2, pp. 288 300, Mar. 2008.

[8] M. A. Pego-Guerra, W. Zhang, and W. Ip, "Robust management of virtual enterprises," in Proc. ASME Int. Des. Eng. Tech. Conf. Comput. Inf. Eng. Conf., Montreal, QC, Canada, Aug. 15-18, 2010, pp. 299-306.

[9] X. Liu, Y. Tu, W. Zhang, R. Deters, and C. Chai, "A generic architecture of the networked critical infrastructure system," in Proc. 3rd Conf. Critical Infrastructure, Old Town Alexandria, VA, USA, Sep. 24-27, 2006. [Online]. Available: http://homepage.usask.ca/ $\sim$ wjz485/Paper\%20download/A\%20Generic\%20arch

[10] R. R. Muddada, "Towards resilient supply chain networks," M.S. thesis, Dept. Mech. Eng., Univ. Saskatchewan, Saskatoon, SK, Canada.

[11] J. C Biolchini, P. G. Mian, A. C. C Natali, T. U. Conte, and G. H. Travassos, "Scientific research ontology to support systematic 
review in software engineering," Adv. Eng. Informat., vol. 21, no. 2, pp. 133-151, Apr. 2007.

[12] H. M. Cooper, Integrating Research: A Guide for Literature Reviews, 2nd ed. Beverly Hills, CA, USA: Sage, 1989.

[13] M. A. Crowther and D. J. Cook, "Trials and tribulations of systematic reviews and meta-analysis," Hematology, vol. 2007, no. 1, pp. 493-497, Jan. 2007.

[14] D. Denyer and A. Neely, "Introduction to special issue: Innovation and productivity performance in the U.K.," Int. J. Manag. Rev., vol. 5/6, no. 3/4, pp. 131-135, Sep. 2004.

[15] D. Tranfield, D. Denyer, and P. Smart, "Towards a methodology for developing evidence-informed management knowledge by means of a systematic review," British J. Manag., vol. 14, no. 3, pp. 207-222, Sep. 2003.

[16] J. DeCoster Meta-analysis notes, 2004. Retrieved from [Online]. Available: http://www.stat-help.com/notes.html

[17] M. Christopher, "The agile supply chain: Competing in volatile markets," Ind. Marketing Manag., vol. 29, no. 1, pp. 37-44, Jan. 2000.

[18] R. Lamming, T. Johnsen, J. Zheng, and C. Harland, "An initial classification of supply networks," Int. J. Oper. Prod. Manag., vol. 20, no. 6, pp. 675-691, 2000.

[19] R. K. Oliver and M. D. Webber, "Supply chain management: Logistics catches up with strategy," in Logistics: The Strategic Issues, M. G. Christopher, Ed. London, U.K.: Chapman \& Hall, 1992, pp. $63-75$

[20] J. B. Houlihan, "Supply chain management," in Proc. 19th Int. Tech. Conf. BPICS, 1984, pp. 101-110, BPICS.

[21] J. P. Womack, D. T. Jones, and D. Roos, The Machine That Changed the World. London, U.K.: Macmillan, 1990.

[22] J. P. Womack and D. T. Jones, Lean Thinking: Banish Waste and Create Wealth in your Corporation. New York, NY, USA: Simon and Schuster, 1996.

[23] C. M. Harland and J. Clark, "Effectiveness framework for supply chain management," Comput. Integr. Manuf. Syst., vol. 3, no. 4, pp. 196-207, Nov. 1990.

[24] M. G. Christopher, Logistics and Supply Chain Management. London, U.K.: Pitman, 1992.

[25] D. J. Bowersox and D. J. Closs, Logistical Management: The Integrated Supply Chain Process. New York, NY, USA: McGraw-Hill, 1996.

[26] P. Zipkin, "The limits of mass customization," MIT Sloan Manag. Rev., vol. 42 , no. 3, pp. 81-87, 2001.

[27] R. Shah and P. T. Ward, "Lean manufacturing: Context, practice bundles, performance," J. Oper. Manag., vol. 21, no. 2, pp. 129-149, Mar. 2003.

[28] A. X. Zhang, "Demand fulfillment rates in an assemble-to-order system with multiple products and dependent demands," Prod. Oper. Manag., vol. 6, no. 3, pp. 309-324, Sep. 1997.

[29] M. A. Pego-Guerra, "Analysis and Design of Virtual Enterprises," Ph.D. dissertation, Univ. Saskatchewan, Saskatoon, SK, Canada, 2005.

[30] A. Meyer and P. Taylor, "E-commerce-An introduction," Comput. Control Eng. J., vol. 11, no. 3, pp. 107-108, 2000.

[31] H. Walker, "The virtual organisation: A new organisational form?" Int. J. Netw. Virtual Org., vol. 3, no. 1, pp. 25-41, Jan. 2005.

[32] A. Banerjee, B. S. Sarkar, and S. K. Mukhopadhyay, "Multiple decoupling point paradigms in a global supply chain syndrome: A relational analysis," Int. J. Prod. Res., vol. 50, no. 11, pp. 3051-3065, 2012.

[33] K. Nagdi, Rubber as Engineering Material: Guideline for Users. Munich, Germany: Hanser Publisher, 1993.

[34] S. S. Luthar, D. Cicchetti, and B. Becker, "The construct of resilience: A critical evaluation and guidelines for future work," Child Development, vol. 71, no. 3, pp. 543-562, May/Jun. 2000.

[35] G. A. Bonanno and A. D. Mancini, "The human capacity to thrive in the face of potential trauma," Pediatrics, vol. 121, no. 2, pp. 369-375, Feb. 2008.

[36] C. S. Holling, "Engineering resilience vs. ecological resilience," in Engineering Within Ecological Constraints, P. C. Schulze, Ed. Washington, DC, USA: National Academy of Sciences-Nat. Res. Council, 1996, pp. 31-43.

[37] J. C. Laprie, "From dependability to resilience," in Proc. Int. Conf. DSN, Anchorage, AK, USA, 2008, pp. G8-G9.

[38] C. S. Holling, "Resilence and stability of ecological systems," Annu. Rev. Ecology Syst., vol. 4, pp. 1-23, 1973.

[39] J. P. G. Sterbenz et al., "Resilience and survivability in communication networks: Strategies 'Principles, survey of disciplines'," Comput. Netw., vol. 54 , no. 8, pp. 1245-1265, Jun. 2010.

[40] G. Hamel and L. Valikangas, "The quest for resilience," Harvard Bus. Rev., vol. 81, no. 9, pp. 52-63, Sep. 2003.
[41] W. J. Zhang and Y. Lin, "Principles of design of resilient systems and its application to enterprise information systems," Enterprise Inf. Syst., vol. 4, no. 2, pp. 99-110, 2010.

[42] E. Hollnagel, D. D. D. Woods, and N. Leveson, Resilience Engineering: Concepts and Precepts. Aldershot, U.K.: Ashgate, 2006.

[43] J. W. Wang, F. Gao, and W. H. Ip, "Measurement of resilience and its application to enterprise information systems," Enterprise Inf. Syst., vol. 4, no. 2, pp. 215-223, May 2010.

[44] W. J. Zhang and C. A. Van. Luttervelt, "Towards a resilient manufacturing system," Ann. CIRP, vol. 60, no. 1, pp. 469-472, 2011.

[45] J. W. Wang, W. H. Ip, and W. J. Zhang, "An integrated road construction and resource planning approach to the evacuation of victims from single source to multiple destinations," IEEE Trans. Intell. Transp. Syst., vol. 11, no. 2, pp. 277-289, Jun. 2010.

[46] J. W. Wang, H. F. Wang, W. J. Zhang, W. H. Ip, and K. Furuta, "Evacuation planning based on the contraflow technique with consideration of evacuation priorities and traffic setup time," IEEE Trans. Intell. Transp. Syst., vol. 11, no. 2, pp. 277-289, Mar. 2013.

[47] R. Bhamra, S. Dani, and K. Burnard, "Resilience: The concept, a literature review and future directions," Int. J. Prod. Res., vol. 49, no. 18, pp. 5375-5393, 2011.

[48] C. A. Billington and T. C. Davis, "Manufacturing strategy analysis: Models and practice," Omega, vol. 20, no. 5/6, pp. 587-595, Sep.-Nov. 1992.

[49] J. Padillo, R. Ingalls, and S. Brown, "A strategic decision support system for supply network design and management in the semiconductor industry," Comput. Ind. Eng., vol. 29, no. 1-4, pp. 443-447, 1995.

[50] A. Huchzermeier and M. A. Cohen, "Valuing operational flexibility under exchange rate risk," Oper. Res., vol. 44, no. 1, pp. 100-113, 1996.

[51] H. L. Corrêa and N. G. M. De Miranda, "Supply network management in the Brazilian automotive industry," Integr. Manuf. Syst., vol. 9, no. 5 , pp. 261-271, 1998.

[52] C. Chandra, "Enterprise architectural framework for supply-chain integration," in Proc. Ind. Eng. Res. Conf., 1997, pp. 873-878.

[53] F. Lin, G. W. Tan, and M. J. Shaw, "Modeling supply-chain networks by a multi-agent system," in Proc. Hawaii Int. Conf. Syst. Sci., 1998, vol. 5, pp. 105-114.

[54] A. Ross, M. A. Venkataramanan, and K. W. Ernstberger, "Reconfiguring the supply network using current performance data," Decision Sci. vol. 29 , no. 3 , pp. $707-724,1998$

[55] F. Lin and M. J. Shaw, "Reengineering the order fulfillment process in supply chain networks," Int. J. Flexible Manuf. Syst., vol. 10, no. 3, pp. 197-229, Jul. 1998.

[56] M. Srinivasan and Y. B. Moon, "A comprehensive clustering algorithm for strategic analysis of supply chain networks," Comput. Ind. Eng., vol. 36, no. 3, pp. 615-633, Jul. 1999.

[57] J. Gjerdrum, N. Shah, and L. G. Papageorgiou, "A combined optimization and agent-based approach to supply chain modelling and performance assessment," Prod. Planning Control, vol. 12, no. 1, pp. 81-88, 2001.

[58] W. C. Chu, J.-N. Chen, C.-Y. Lee, and Y. Hongji, "Implementing an agent system using N-tier pattern-based framework," in Proc. 25th Annu. Int. COMPSAC, Chicago, IL, USA, Oct. 8-12, 2001, pp. 451-456.

[59] P. Tsiakis, N. Shah, and C. C. Pantelides, "Design of multi-echelon supply chain networks under demand uncertainty," Ind. Eng. Chem. Res., vol. 40, no. 16, pp. 3585-3604, 2001.

[60] J. W. Wang, H. F. Wang, W. J. Zhang, W. H. Ip, and K. Furuta, "On a unified definition of the service system: What is its identity?" IEEE Syst. J., vol. 8, no. 3, pp. 821-826, Sep. 2014.

[61] L. Wuming, H. Pingyang, and G. Fei, "Study on system modeling and analyzing of supply chain network," in Proc. IEEE ICAL, 2009, pp. 1598-1602, Paper presented at the, Art. No. 5262715.

[62] A. Dubois, K. Hulthén, and A. C. Pedersen, "Supply chains and interdependence: A theoretical analysis," J. Purchasing Supply Manag., vol. 10, no. 1, pp. 3-9, Jan. 2004.

[63] F. T. S. Chan, R. Bhagwat, and S. Wadhwa, "Study on suppliers' flexibility in supply chains: Is real-time control necessary?" Int. J. Prod. Res., vol. 47, no. 4, pp. 965-987, 2009

[64] M. Zhou, D. T. Wang, and I. Mayk, "Combining Petri nets and objectoriented design technology for command and control systems," Int. J. Intell. Control Syst., vol. 2, no. 2, pp. 287-300, 1998.

[65] K. Dogan and M. Goetschalckx, "A primal decomposition method for the integrated design of multi-period production-distribution systems," IIE Trans., vol. 31, no. 11, pp. 1027-1036, Nov. 1999. 
[66] H. Min and E. Melachrinoudis, "The relocation of a hybrid manufacturing/distribution facility from supply chain perspectives: A case study," Omega, vol. 27, no. 1, pp. 75-85, Feb. 1999.

[67] S. A. Mirhassani, C. Lucas, G. Mitra, E. Messina, and C. A. Poojari, "Computational solution of capacity planning models under uncertainty," Parallel Comput., vol. 26, no. 5, pp. 511-538, Mar. 2000.

[68] M. Dong and F. F. Chen, "Process modeling and analysis of manufacturing supply chain networks using object-oriented Petri nets," Robot. Comput.-Integr. Manuf., vol. 17, no. 1/2, pp. 121-129, Feb. 2001.

[69] N. R. S. Raghavan and N. Viswanadham, "Generalized queueing network analysis of integrated supply chains," Int. J. Prod. Res., vol. 39, no. 2, pp. 205-224, 2001.

[70] G. Zhou, H. Min, and M. Gen, "The balanced allocation of customers to multiple distribution centers in the supply chain network: A genetic algorithm approach," Comput. Ind. Eng., vol. 43, no. 1/2, pp. 251-261, Jul. 2002.

[71] J. Dong, D. Zhang, and A. Nagurney, "A supply chain network equilibrium model with random demands," Eur. J. Oper. Res., vol. 156, no. 1, pp. 194-212, 2004.

[72] E. Eskigun et al., "Outbound supply chain network design with mode selection lead times and capacitated vehicle distribution centers," Eur. J. Oper. Res., vol. 165, no. 1, pp. 182-206, Aug. 2005.

[73] M. T. Melo, S. Nickel, and F. S. Saldanha Da Gama, "Dynamic multi-commodity capacitated facility location: A mathematical modeling framework for strategic supply chain planning," Comput. Oper. Res., vol. 33, no. 1, pp. 181-208, Jan. 2006.

[74] J. Choi, H. Lee, S. K. Heo, and J. Lee, "A mathematical programming for supply chain network design," in Proc. Int. Joint Conf., 2006, pp. $170-174$.

[75] N. Liu and J. Zhou, "Supply chain network equilibrium model with capacity constraints," J. Southeast Univ. (English Edition), vol. 23, pp. 8388, 2007.

[76] M. Dong and Y. Peng, "The robustness metrics for supply chain network design," Shanghai Jiaotong Daxue Xuebao/J. Shanghai Jiaotong Univ., vol. 41, no. 7, pp. 1092-1096, 2007.

[77] S. W. Chiou, "A combinatorial approximation algorithm for supply chain network flow problem," Appl. Math. Comput., vol. 186, no. 2, pp. 15261536, Mar. 2007

[78] H. E. Romeijn, J. Shu, and C. Teo, "Designing two-echelon supply networks," Eur. J. Oper. Res., vol. 178, no. 2, pp. 449-462, Apr. 2007.

[79] M. T. Melo, S. Nickel, and F. Saldanha-da-Gama, "Facility location and supply chain management-A review," Eur. J. Oper. Res., vol. 196, no. 2, pp. 401-412, Jul. 2009.

[80] Z. Che, Z. H. Che, and T. A. Hsu, "Cooperator selection and industry assignment in supply chain network with line balancing technology," Expert Syst. Appl., vol. 36, no. 7, pp. 10381-10387, Sep. 2009.

[81] T. M. Rupp and M. Ristic, "Fine planning for supply chains in semiconductor manufacture," J. Mater. Process. Technol., vol. 107, no. 1-3, pp. 390-397, Nov. 2000.

[82] A. Nagurney, J. Dong, and D. Zhang, "A supply chain network equilibrium model," Transp. Res. Part E, Logistics Transp. Rev., vol. 38, no. 5, pp. 281-303, Sep. 2002.

[83] A. Cakravastia, I. S. Toha, and N. Nakamura, "A two-stage model for the design of supply chain networks," Int. J. Prod. Econ., vol. 80, no. 3, pp. 231-248, Dec. 2002.

[84] R. A. Lancioni, M. F. Smith, and H. J. Schau, "Strategic Internet application trends in supply chain management," Ind. Marketing Manag., vol. 32, no. 3, pp. 211-217, Apr. 2003.

[85] C. L. Chen, B. W. Wang, and W. C. Lee, "Multi-objective optimization for a multi-enterprise supply chain network," Ind. Eng. Chem. Res., vol. 42, no. 9, pp. 1879-1889, 2003.

[86] K. H. Wathne and J. B. Heide, "Relationship governance in a supply chain network," J. Marketing, vol. 68, no. 1, pp. 73-89, Jan. 2004.

[87] C. L. Chen and W. C. Lee, "Multi-objective optimization of multiechelon supply chain networks with uncertain product demands and prices," Comput. Chem. Eng., vol. 28, no. 6/7, pp. 1131-1144, Jun. 2004.

[88] F. T. S. Chan and H. K. Chan, "A new model for manufacturing supply chain networks: A multiagent approach," Proc. Inst. Mech. Eng. Part B, J. Eng. Manuf., vol. 218, no. 4, pp. 443-454, Apr. 2004.

[89] V. Jain, M. K. Tiwari, and F. S. T. Chan, "Evaluation of the supplier performance using an evolutionary fuzzy-based approach," J. Manuf. Technol. Manag., vol. 15, no. 8, pp. 735-744, 2004.

[90] T. Santoso, S. Ahmed, M. Goetschalckx, and A. Shapiro, "A stochastic programming approach for supply chain network design under uncertainty," Eur. J. Oper. Res., vol. 167, no. 1, pp. 96-115, Nov. 2005
[91] F. Altiparmak, M. Gen, L. Lin, and T. Paksoy, "A genetic algorithm approach for multi-objective optimization of supply chain networks," Comput. Ind. Eng., vol. 51, no. 1, pp. 196-215, Sep. 2006.

[92] J. Jiao, X. You, and A. Kumar, "An agent-based framework for collaborative negotiation in the global manufacturing supply chain network," Robot. Comput.-Integr. Manuf., vol. 22, no. 3, pp. 239-255, Jul. 2006.

[93] R. Patnayakuni, A. Rai, and N. Seth, "Relational antecedents of information flow integration for supply chain coordination," J. Manag. Inf. Syst., vol. 23, no. 1, pp. 13-49, 2006.

[94] D. Y. Sha and Z. H. Che, "Supply chain network design: Partner selection and production/distribution planning using a systematic model," J. Oper. Res. Soc., vol. 57, no. 1, pp. 52-62, Jan. 2006.

[95] H. Ding, L. Benyoucef, and X. Xie, "A simulation-based multi-objective genetic algorithm approach for networked enterprises optimization," Eng. Appl. Artif. Intell., vol. 19, no. 6, pp. 609-623, Sep. 2006.

[96] F. Lin, G. W. Tan, and M. J. Shaw, "Multi-agent enterprise modeling," J. Org. Comput. Electron. Commerce, vol. 9, no. 1, pp. 7-32, 1999.

[97] A. Cox, "The art of the possible: Relationship management in power regimes and supply chains," Supply Chain Manag., vol. 9, no. 5, pp. 346356,2004

[98] G. Fandel and M. Stammen, "A general model for extended strategic supply chain management with emphasis on product life cycles including development and recycling," Int. J. Prod. Econ., vol. 89, no. 3, pp. $293-$ 308, Jun. 2004.

[99] C. Ranganathan, J. S. Dhaliwal, and T. S. H. Teo, "Assimilation and diffusion of web technologies in supply-chain management: An examination of key drivers and performance impacts," Int. J. Electron. Commerce, vol. 9, no. 1, pp. 127-161, 2004.

[100] B. M. Beamon and C. Fernandes, "Supply-chain network configuration for product recovery," Prod. Planning Control, vol. 15, no. 3, pp. 270 281,2004

[101] A. Surana, S. Kumara, M. Greaves, and U. N. Raghavan, "Supply-chain networks: A complex adaptive systems perspective," Int. J. Prod. Res., vol. 43, no. 20, pp. 4235-4265, 2005.

[102] N. R. Sanders, "IT alignment in supply chain relationships: A study of supplier benefits," J. Supply Chain Manag., vol. 41, no. 2, pp. 4-13, May 2005.

[103] J. W. Wang, W. H. Ip, R. R. Muddada, J. L. Huang, and W. J. Zhang, "On Petri net implementation of proactive resilient holistic supply chain networks," Int. J. Adv. Manuf. Technol., vol. 69, no. 1-4, pp. 427-437, Oct. 2013.

[104] K. Kleijnen and M. Smits, "Performance metrics in supply chain management," J. Oper. Res. Soc., vol. 54, no. 5, pp. 507-514, 2003.

[105] A. Villa, "Emerging trends in large-scale supply chain management," Int J. Prod. Res., vol. 40, no. 15, pp. 3487-3498, 2002.

[106] J. Blackhurst, T. Wu, and P. O'Grady, "Network-based approach to modelling uncertainty in a supply chain," Int. J. Prod. Res., vol. 42, no. 8, pp. 1639-1658, 2007.

[107] M. Christopher and H. Peck, "Building the resilient supply chain," Int. J. Logistics Manag., vol. 15, no. 2, pp. 1-13, 2004.

[108] Y. Sheffi, "Building a resilient supply chain," Harvard Bus. Rev., vol. 1, no. 8, pp. 1-14, Oct. 3-5, 2005.

[109] Deloitte, "Supply chain resilience: A risk intelligent approach to managing global supply chains," Int. J. Prod. Res., vol. 43, no. 19, pp. 40674081, 2005.

[110] H. Carvalho and V. C. Machado, "Designing principles to create resilient Supply Chains," in Proc. Ind. Eng. Res. Conf., Nashville, TN, USA, 2007, pp. 186-191.

[111] J. Blackhurst, C. W. Craighead, D. Elkins, and R. B. Hanfield, "An empirically derived agenda of critical research issues for managing supply-chain disruptions," Int. J. Prod. Res., vol. 43, no. 19, pp. 40674081, 2005

[112] S. N. Wagner and N. Neshat, "Assessing the vulnerability of supply chains using graph theory," Int. J. Prod. Econ., vol. 126, pp. 121-129, 2009.

[113] X. Y. Kong and X. Y. Li, "Creating the resilient supply chain: The role of knowledge management resources," in Proc. 4th Int. Conf. WiCOM, Oct. 1-4, 2008, pp. 12-14.

[114] J. X. Xu, "Managing the risk of supply chain disruption: Towards a resilient approach of supply chain management," in Proc. ISECS Int. Colloquium Comput., Commun., Control, Manag., 2008, pp. 3-7.

[115] G. Ji and C. H. Zhu, "Study on supply chain disruption risk management strategies and model," in Proc. Int. Conf. Service Syst. Service Manag., Melbourne, VIC, Australia, Jun. 30-Jul. 2, 2008, pp. 1-6.

[116] J. Hammant and A. Braithwaite, "Supply chain agility-Managing the consequences of increased vulnerability," Int. J. Agile Manuf., vol. 10, pp. 103-112, 2007. 
[117] Y. Sheffi and J. Rice, "A supply chain view of the resilient enterprise," MIT Sloan Manag. Rev., vol. 47, no. 1, pp. 41-48, 2005.

[118] W. Klibi, A. Martel, and A. Guitouni, "The design of robust valuecreating supply chain networks: A critical review," Eur. J. Oper. Res., vol. 203, pp. 283-293, 2010.

[119] J. Rice and F. Caniato, "Building a secure and resilient supply chain," Supply Chain Manag. Rev., vol. 5, pp. 22-30, 2003.

[120] P. Barnes and R. Oloruntoba, "Assurance of security in maritime supply chains: Conceptual issues of vulnerability and crisis management," $J$. Int. Manag., vol. 11, no. 4, pp. 519-540, Dec. 2005

[121] C. W. Craighead, J. Blackhurst, M. J. Rungtusanatham, and R. B. Handfield, "The severity of supply chain disruptions: Design characteristics and mitigation capabilities," Decision Sci., vol. 38, no. 1, pp. 131-156, Feb. 2007.

[122] L. Deleris, D. Elkins, and M. E. Paté-Cornell, "Analyzing losses from hazard exposure: A conservative probabilistic estimate using supply chain risk simulation," in Proc. Winter Simul. Conf., 2004, pp. 323-330.

[123] T. S. Glickman and S. C. White, "Security, visibility and resilience: The keys to mitigating supply chain vulnerabilities," Int. J. Logistics Syst. Manag., vol. 2, no. 2, pp. 107-119, 2006.

[124] V. Babich, "Vulnerable options in supply chains: Effect of the supplier competition," Naval Res. Logistics, vol. 53, no. 7, pp. 656-673, 2006.

[125] V. Babich, A. N. Burnetas, and P. H. Ritchken, "Competition and diversification effects in supply chains with supplier default risk," Manuf. Service Oper. Manag., vol. 9, no. 2, pp. 123-146, 2007.

[126] C. S. Tang and B. Tomlin, "The power of flexibility for mitigating supply chain risks," Int. J. Prod. Econ., vol. 116, no. 1, pp. 12-27, 2008.

[127] K. Mitra, R. D. Gudi, S. C. Patwardhan, and G. Sardar, "Towards Resilient supply chains: Uncertainty analysis using fuzzy mathematical programming," Chem. Eng. Res. Des., vol. 87, no. 7, pp. 967-981, Jul. 2009.

[128] Y. P. Jiang, L. Zhao, and S. N. Sun, "A resilient strategy for meatfood supply chain network design," in Proc. IEEE Int. Conf., Hongkong, Dec. 8-11, 2009, pp. 1479-1483.

[129] H. S. Yu and L. D. Zhao, "Supplier selection and order splitting modeling in the presence of supplier capacity and resilience," J. Southeast Univ. (English Edition), vol. 24, no. 1, pp. 104-109, 2008.

[130] N. Bakshi and P. R. Kleindorfer, "Co-opetition and investment for supply-chain resilience," Prod. Oper. Manag., vol. 18, no. 6, pp. 583603, 2009.

[131] A. Diabat, K. Govindan, and V. Panicker, "Supply chain risk management and its mitigation in a food industry," Int. J. Prod. Res., vol. 50, no. 3, pp. 3039-3050, 2012.

[132] E. Iakovoua, D. Vlachosa, and A. Xanthopoulosa, "A stochastic inventory management model for a dual sourcing supply chain with disruptions," Int. J. Syst. Sci., vol. 41, pp. 315-324, 2010.

[133] J. M. Slingo, A. J. Challinor, B. J. Hoskins, and T. R. Wheeler, "Introduction: Food crops in a changing climate," Philosoph. Trans. Roy. Soc. B-Biological Sci., vol. 360, pp. 1983-1989, 2005.

[134] E. J. Lodree and S. Taskin, "Supply chain planning for hurricane response with wind speed information updates," Comput. Oper. Res., vol. 36, no. 1, pp. 2-15, Jan. 2009.

[135] R. Sarathy, "Security and the global supply chain," Transp. J., vol. 45, no. 4, pp. 28-52, 2006.

[136] S. Dynes, "Information risk management and resilience," IFIP Adv. Inf. Commun. Technol., vol. 311, pp. 3-17, 2009.

[137] A. Mohan, "Confidential and Resilient Store of Persistent Web Objects," M.S. Thesis, Dept. Comput. Sci., University of Miami, Coral Gables, FL, USA, 2009.

[138] D. More and A. Babu Subash, "Supply chain flexibility: A state-of-theart survey," Int. J. Serv. Oper. Manag., vol. 5, no. 1, pp. 29-65, 2009.

[139] C. I. Enyinda and D. Tolliver, "Taking counterfeits out of the pharmaceutical supply chain in Nigeria: Leveraging multilayer mitigation approach," J. African Bus., vol. 10, no. 2, pp. 218-234, 2009.

[140] J. H. Thun and D. Hoenig, "An empirical analysis of supply chain risk management in the German automotive industry," Int. J. Prod. Econ., vol. 131, no. 1, pp. 242-249, 2009.

[141] E. Alonso, F. R. Field, R. Roth, and R. E. Kirchain, "Strategies to address risks of platinum scarcity for supply chain downstream firms," in Proc. IEEE ISSST, 2009, pp. 1-6.

[142] M. A. Lara Gracia and Y. N. Shimon, "Conflict resolution in supply chain security," Int. J. Value Chain Manag., vol. 3, no. 2, pp. 168-186, 2008.

[143] G. Thamilarasu and R. Sridhar, "Intrusion detection in RFID systems," in Proc. IEEE MILCOM, Nov. 2008, pp. 1-7.
[144] D. Roussinov and M. Chau, "Combining information seeking services into a meta supply chain of facts," J. Assoc. Inf. Syst., vol. 9, no. 3/4, pp. $175-199,2008$.

[145] R. H. Weber, "Internet of things-New security and privacy challenges," Comput. Law Security Rev., vol. 26, no. 1, pp. 23-30, Jan. 2010.

[146] A. M. Knemeyer, W. Zinn, and C. Eroglu, "Proactive planning for catastrophic events in supply chains," J. Oper. Manag., vol. 27, no. 2, pp. 141-153, Apr. 2009.

[147] S. Ratick, B. Meacham, and Y. Aoyama, "Locating backup facilities to enhance supply chain disaster resilience," Growth Change, vol. 39, no. 4, pp. 642-666, 2008.

[148] Y. Yan, L. Xiao, and X. T. Zhuang, "Resilient supply chain emergency management strategy based on node fails," Control Decision, vol. 25, no. 1, pp. 25-30, 2010.

[149] C. Liu and C. Ji, "Resilience of all-optical network architectures under in-band crosstalk attacks: A probabilistic graphical model approach," IEEE J. Sel. Areas Commun., vol. 25, no. 3, pp. 2-17, Apr. 2007.

[150] S. Vellema, D. Loorbach, and N. P. Van, "Strategic transparency between food chain and society: Cultural perspective images on the future of farmed salmon," Prod. Planning Control, vol. 17, no. 6, pp. 624-32, 2006.

[151] A. Boin, P. Kelle, and D. C. Whybark, "Resilient supply chains for extreme situations: Outlining a new field of study," Int. J. Prod. Econ., vol. 126, no. 1, pp. 1-6, 2010.

[152] G. T. Stewart, R. Kolluru, and M. Smith, "Leveraging public-private partnerships to improve community resilience in times of disaster," Int. J. Phys. Distrib. Logistics Manag., vol. 39, no. 5, pp. 343-364, 2009.

[153] J. J. Roh, H. Min, and P. Hong, "A co-ordination theory approach to restructuring the supply chain: An empirical study from the focal company perspective," Int. J. Prod. Res., vol. 49, no. 15, pp. 4517-4541, 2011.

[154] R. Piplani and A. Saraswat, "Robust optimization approach to the design of service networks for reverse logistics," Int. J. Prod. Res., vol. 50, no. 5 , pp. 1424-1437, 2012.

[155] D. Ivanov, "An adaptive framework for aligning (re)planning decisions on supply chain strategy, design, tactics, operations," Int. J. Prod. Res. vol. 48, no. 13, pp. 3999-4017, 2010.

[156] J. W. Wang, "Towards a Resilient Networked Service System," Ph.D. thesis, Dept. Mech. Eng., Univ. Saskatchewan, Saskatoon, SK, Canada, 2013.

[157] G. A. Akyuz and T. E. Erkan, "Supply chain performance measurement A literature review," Int. J. Prod. Res., vol. 48, no. 17, pp. 5137-5155, 2010.

[158] A. Vanichchinchai and B. Legl, "The impact of total quality management on supply chain management and firm's supply performance," Int. J. Prod. Res., vol. 49, no. 11, pp. 3405-3424, 2011.

[159] H. Lee, P. Paddy, and W. Seungjin, "The Paralysing Curse of the Bullwhip Effect in a Supply Chain," Sloan Manag. Rev., 1997.

[160] P. Wangphanich, S. Kara, and B. Kayis, "Analysis of the bullwhip effect in multi-product, multi-stage supply chain systems-A simulation approach," Int. J. Prod. Res., vol. 48, no. 15, pp. 4501-4517, 2010.

[161] J. Forrester, Industrial Dynamics. Cambridge, MA, USA: MIT press, 1961.

[162] W. J. Zhang et al., "Social network analysis of the vulnerabilities of interdependent critical infrastructures," Int. J. Critical Infrastructures, vol. 4, no. 3, pp. 256-266, 2008.

[163] A. L. Barabási and R. Albert, "Emergence of scaling in random networks," Science, vol. 286, no. 5439, pp. 509-512, Oct. 15, 1999.

[164] T. Murata, "Petri nets: Properties, analysis and applications," Proc. IEEE, vol. 77, no. 4, pp. 541-580, Apr. 1989.

[165] W. J. Zhang, Q. Li, Z. M. Bi, and X. F. Zha, "A generic Petri net model for flexible manufacturing systems and its use for FMS control software testing," Int. J. Prod. Res., vol. 38, no. 5, pp. 1109-1131, 2000.

[166] T. Wu, J. Blackhurst, and P. O'grady, "Methodology for supply chain disruption analysis," Int. J. Prod. Res., vol. 45, no. 7, pp. 1665-1682, 2007.

[167] L. F. Zhang, X. You, J. X. Jiao, and P. Helo, "Supply chain configuration with co-ordinated product, process and logistics decisions: An approach based on Petri nets," Int. J. Prod. Res., vol. 47, no. 23, pp. 6681-6706, 2009.

[168] G. Q. Huang, Lau, S. K. Jason, and K. L. Mak, "The impacts of sharing production information on supply chain dynamics: A review of the literature," Int. J. Prod. Res., vol. 41, no. 7, pp. 1483-1517, 2010.

[169] T. Wakolbinger and J. M. Cruz, "Supply chain disruption risk management through strategic information acquisition and sharing and risksharing contracts," Int. J. Prod. Res., vol. 49, no. 13, pp. 4063-4084, 2011. 
[170] E. Simangunsong, L. C. Hendry, and M. Stevenson, "Supply-chain uncertainty: A review and theoretical foundation for future research," Int. J. Prod. Res., vol. 50, no. 16, pp. 4493-4523, 2012.

[171] X. D. Zhao, J. X. Xie, and W. J. Zhang, "The impact of information sharing and ordering co-ordination on supply chain performance," Supply Chain Manag., Int. J., vol. 7, no. 1, pp. 24-40, Feb. 24-40, 2001.

[172] J. W. Wang, D. Liu, W. H. Ip, Ws Zhang, and R. Deters, "Integration of system-dynamics, aspect-programming, objective-orientation in system information modeling," IEEE Trans. Ind. Informat., vol. 10, no. 2, pp. 847-853, May 2014.

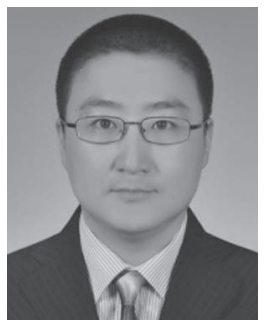

Junwei Wang received the Ph.D. degree in mechanical engineering from the University of Saskatchewan, Saskatoon, SK, Canada, in 2013 and the Ph.D. degree in systems engineering from Northeastern University, Shenyang, China, in 2006.

From 2011 to 2013, he was a Japan Society for the Promotion of Science Postdoctoral Fellow with the Department of Systems Innovation, School of Engineering, The University of Tokyo, Tokyo, Japan. Since March 2014, he has been an Assistant Professor with the Department of Industrial and Manufacturing Systems Engineering, Faculty of Engineering, The University of Hong Kong, Pokfulam, Hong Kong. He is the author or coauthor of 18 refereed technical papers and refereed conference papers, and he is a coauthor of a book on optimization algorithms. His current research interests include modeling and optimization for resilient complex networked systems.

Raja R. Muddada received the Master's degree from the University of Saskatchewan, Saskatoon, SK, Canada.

$\mathrm{He}$ is currently with the Advanced Engineering Design Laboratory, Department of Mechanical Engineering, College of Engineering, University of Saskatchewan. He is the author or coauthor of several technical papers in refereed journals and conferences. His research interests include resilient supply chain systems.

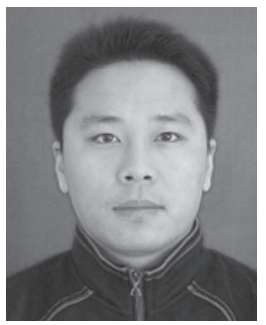

Hongfeng Wang received the B.Sc. degree in industrial engineering and the M.Sc. and Ph.D. degrees in system engineering from Northeastern University, Shenyang, China, in 2001, 2004, and 2007, respectively.

$\mathrm{He}$ is currently an Associate Professor with the Institute of System Engineering, Northeastern University. He is the author or coauthor of several refereed technical papers and refereed conference papers, and he is a coauthor of a book on optimization algorithms. His major research interests include evolutionary algorithms, mimetic computing, computational intelligence in dynamic environments, and the modeling of the optimization of complex systems.

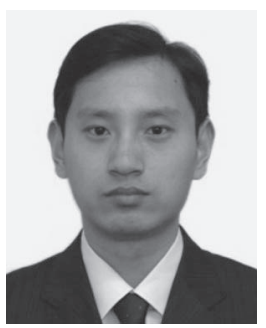

Jinliang Ding (M'09-SM'14) received the B.S., M.S., and Ph.D. degrees in control theory and control engineering from Northeastern University, Shenyang, China, in 2001, 2004, and 2012, respectively.

$\mathrm{He}$ is currently a Professor with the State Key Laboratory of Synthetical Automation for Process Industry, Northeastern University. He is the author or coauthor of more than 60 refereed journal papers and refereed papers at international conferences. His current research interests include modeling, plantwide control, and optimization for complex industrial systems, and multiobjective evolutionary algorithms and its application.

Dr. Ding was the recipient of the Science and Technology Award of the Chinese Ministry of Education in 2006, the Control Engineering Practice Paper Prize Award in 2011-2013, and the National Award for Technological Invention in 2013.

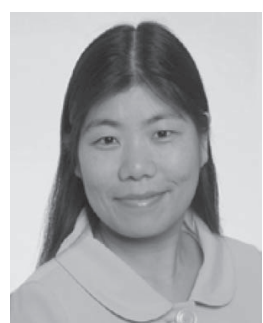

Yingzi Lin received the Ph.D. degree in mechanical engineering from the University of Saskatchewan, Saskatoon, SK, Canada, in 2004.

She is currently an Associate Professor with the Department of Mechanical and Industrial Engineering, College of Engineering, Northeastern University, Boston, MA, USA, where she directs the Intelligent Human-Machine Systems Laboratory. She is the author or coauthor of over 100 technical papers in refereed journals and conference proceedings. Her current research interests include human factors in systems and operation management.

Ms. Lin was a recipient of funding from the National Science Foundation (NSF), the Natural Sciences and Engineering Research Council of Canada (NSERC), and major industries. She was a recipient of a few prestigious research awards, including an NSF Faculty Early Career Development (CAREER) Award and an NSERC University Faculty Award.

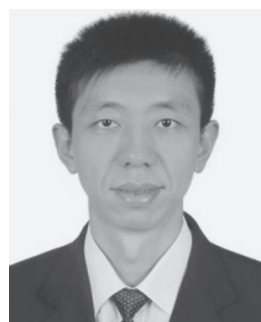

Changli Liu received the Ph.D. degree in mechanical engineering from Northeastern University, Shenyang, China, in 2004.

$\mathrm{He}$ is currently an Associate Professor with the Department of Mechanical Engineering, School of Mechanical and Power Engineering, East China University of Science and Technology, Shanghai, China. $\mathrm{He}$ is also a Visiting Scholar with the University of Saskatchewan, Saskatoon, SK, Canada. He is the author or coauthor of several refereed technical papers and refereed conference papers. His current research interests include the modeling of nonlinear dynamics systems and the condition monitoring and fault diagnosis of turbine machines.

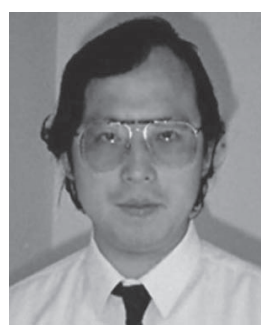

Wenjun Zhang (SM'13) received the Ph.D. degree from Delft University of Technology, Delft, The Netherlands, in 1994

$\mathrm{He}$ is currently a Professor of mechanical engineering with the Advanced Engineering Design Laboratory, Department of Mechanical Engineering, College of Engineering, University of Saskatchewan, Saskatoon, SK, Canada. He is also a Chair Professor with the East China University of Science of Technology, Shanghai, China. He is the author or coauthor of over 320 refereed technical publications, with 193 papers in refereed journals and over 130 papers in refereed conference proceedings in a broad scope of fields, including design and mechatronics, manufacturing, informatics, and human-machine systems. His $h$-index (science citation index) is 22 as of November 2013.

Dr. Zhang is a member of the American Society of Mechanical Engineers (ASME), a Senior Member of the Society of Manufacturing Engineers, and a member of the International Society for Optics and Photonics (SPIE). He has served as a Technical Editor for ASME/IEEE TRANSACTIONS ON MECHATRONICS and an Associate Editor for the International Journal of Systems Science, Enterprise Information Systems. He was the recipient of the Outstanding Researcher Award from the College of Engineering, University of Saskatchewan in 2011 and the Distinguished Graduate Supervisor Award from the University of Saskatchewan in 2012 